\title{
Electrical conductivity degradation of fatigued carbon black reinforced natural rubber composites: Effects of carbon nanotubes and strain amplitudes
}

\author{
E. Harea*, S. Datta, M. Stěnička, R. Stoček \\ Centre of Polymer Systems, Tomas Bata University in Zlín, Tř́ída Tomáše Bati 5678, 76001 Zlín, Czech Republic
}

Received 13 May 2019; accepted in revised form 8 July 2019

\begin{abstract}
The fatigue of rubber products is usually accompanied by undesirable transformation in their properties. The present work was dedicated to the investigation of consequences of fatigue loading on volume electric conductivity of natural rubber (NR) reinforced with $30 \mathrm{phr}$ of fillers composed from various weight combinations of carbon nanotubes (CNTs) and carbon black (CB). Special attention was paid to study the influence of CNTs content on residual electric conductivity and a possible mechanism of fatigue driven rearrangement of hybrid filler network inside of rubber matrix was propounded forward. An increase in the CNTs content over the complete range of concentrations, enhanced the conductivity of fabricated samples up to two orders of magnitude in comparison to rubber compounds without CNTs. All the samples were subjected to harmonic sinusoidal loading at a frequency of $5 \mathrm{~Hz}$ up to $10^{5}$ loading cycles at three different strains of $0.1,0.25$ and 0.5 . Despite very little transformation in the polymer matrix, fatigue caused a progressive degradation of conductivity with an increase in applied strain. It was also found that with the addition and a subsequent increase in the concentration of CNTs, the undesirable reduction of conductivity was significantly arrested. This novel finding added another number to the list of the outstanding properties of CNTs.
\end{abstract}

Keywords: rubber, fatigue, carbon nanotubes, electrical properties, hybrid fillers

\section{Introduction}

Electrical conductivity of rubber compounds gained great interest since the fifties of the last century originating from practical applications for antistatic tires, belts, electric cables and from fundamental relationship between conductivity and filler dispersion and reinforcement [1]. Nowadays, conductive elastomers are intensively studied as promising materials for transducers, sensors and flexible electrodes [2-5] because of their ability to be elastically deformed while still providing some degree of electrical conductivity [6]. Usually, the aiming grade of conductivity is realized by filling an insulating polymer matrix with conductive particles [7]. Among the traditionally used types of fillers, fast development is in the direction of using so called hybrid fillers which often exhibit a synergetic effect in the properties of the composites [8]. Suggestive examples are products from natural rubber based composites filled with carbon nanotubes and carbon black hybrid fillers encompassing noticeable enhancements in mechanical properties such as fracture and fatigue resistance [9], friction and wear [10], electrical properties [2, 11, 12] etc. Higher conductivity of such a composite at lower percolation threshold is achieved due to $\mathrm{CB}$ particles which effectively bridge CNTs surrounded by nonconductive polymer, and contributes to the formation of new electron pathways.

During the service life, flexible electrodes, sensors, transducers, tires and belts are supposed to endure

*Corresponding author, e-mail: harea@utb.cz

(C) BME-PT 
millions of deformation cycles, which can lead to internal micro-failure [13], variation of distances between conductive particles, spatial rearrangements, rotations, possible damage of fillers [6] and changes in the electrical performance of products. That fatigue imposed reorganization of microscopic and mesoscopic structure of carbon black filler in natural rubber was shown in [14]. Presented TEM images demonstrated the destruction of the $\mathrm{CB}$ agglomerates and the rearrangement of $\mathrm{CB}$ aggregates in a string. The changes in the electrical conductivity of elastomer devices based on CNTs and CB incorporated hybrid filler systems after their extensive fatigue are weakly studied until now. Majority of existing studies on this topic were dedicated to in-situ measurements of conductivity/resistivity during deformation [for example 2, 5, 6] at relatively low frequencies and number of cycles.

The present work was focused on the preparation of NR composites with hybrid CNTs and CB fillers through a simple mixing method [10] and investigation of their volume conductivity before and after $10^{5}$ harmonic sinusoidal loading cycles which was supposed to simulate the long term use of such products as mechano-electrical devices. Implemented number of cycles and low deformation amplitudes, discussed in details in the experimental section of the article, were selected in such a way that they fell far below the mechanical fatigue limit [15] of the rubber matrix. Therefore, all fatigue transformations of the material were supposed to be attributed exclusively to filler network changes. Unusually for electrical properties investigations $-5 \mathrm{~Hz}$ frequency of deformation was applied. In each sample, the total amount of fillers was kept at $30 \mathrm{phr}$ level in accordance with simulations [16] which is considered to be the beginning of percolation threshold for $\mathrm{CB}$ fillers in elastomers.

\section{Experimental}

\subsection{Materials}

Natural rubber used in this research was supplied by the Astlett Rubber Inc. (type SMR 20 CV/BP1). Sulphur used as the curing agent, zinc oxide $(\mathrm{ZnO})$ and stearic acid used as activator and co-activator respectively were supplied by Sigma-Aldrich ${ }^{\circledR}$. Industrial grade of carbon black of the type N220 (Cabot Corporation) was used as filler. CBS ( $N$-cyclohexyl-2benzothiazolesulfenamide) was employed as curing accelerator. Toluene used as the swelling solvent in swelling test was supplied by the AnalaR NORMAPUR $^{\circledR}$ ACS. The compounding formulations of the prepared samples along with their short notations are listed in Table 1.

Commonly, CNTs are divided into two categories: single-walled carbon nanotubes (SWCNTs) which consist of a single graphene cylinders, and multiwalled carbon nanotubes (MWCNTs) containing several concentric graphene cylinders. In the present paper MWCNTs were used and are denoted simply as CNTs.

Multi-walled carbon nanotubes with diameter of 10 $20 \mathrm{~nm}$, bulk density $0.02-0.04 \mathrm{~g} / \mathrm{cm}^{3}$ and surface area in the range of $200-400 \mathrm{~m}^{2} / \mathrm{g}$, obtained by catalytic pyrolysis described in [17] were provided by

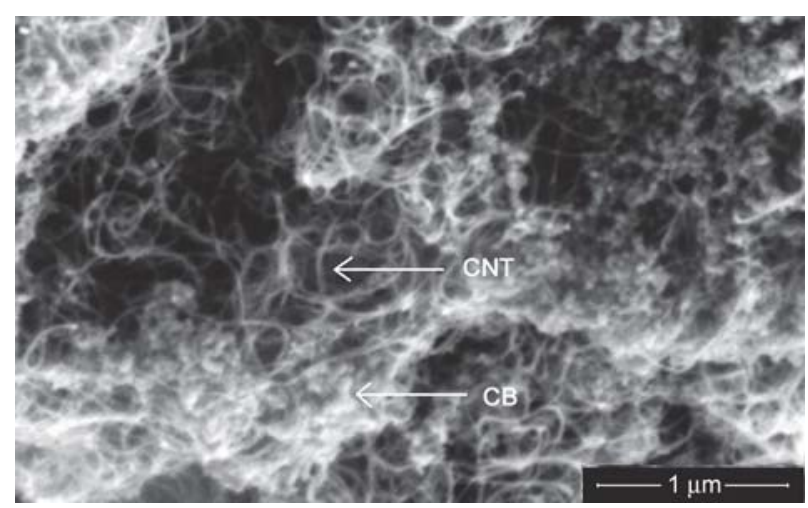

Figure 1. SEM picture of dry mixed CNTs with $\mathrm{CB}$, prepared for sample NR3. Arrows show CNT and CB particles.

Table 1. Samples denotation and composition.

\begin{tabular}{|c|c|c|c|c|c|c|c|}
\hline \multirow{2}{*}{\multicolumn{2}{|c|}{ Compounding formulations }} & NR & $\mathrm{CNT}+\mathrm{CB}$ & CBS & Sulphur & $\mathrm{ZnO}$ & Stearic Acid \\
\hline & & \multicolumn{6}{|c|}{$\begin{array}{l}\text { Content } \\
{[\mathrm{phr}]^{*}}\end{array}$} \\
\hline \multirow{4}{*}{ Short notations } & NR0 & 100 & $0+30$ & 1.0 & 2.5 & 5.0 & 2.0 \\
\hline & NR1 & 100 & $1+29$ & 1.0 & 2.5 & 5.0 & 2.0 \\
\hline & NR3 & 100 & $3+27$ & 1.0 & 2.5 & 5.0 & 2.0 \\
\hline & NR5 & 100 & $5+25$ & 1.0 & 2.5 & 5.0 & 2.0 \\
\hline
\end{tabular}

${ }^{*}[\mathrm{phr}]$ - The compound ingredients are given as parts per 100 parts of rubber by weight. 
Chuiko Institute of Surface Chemistry, National Academy of Sciences of Ukraine. A dry physical mixture of carbon black and CNTs filler is shown in Figure 1.

\subsection{Rubber compounding}

The rubber compounds based on NR filled with $\mathrm{CB}$ and hybrid $\mathrm{CB}+\mathrm{CNT}$ fillers were mixed in a Brabender Plastograph (Brabender GmbH \& Co, Germany). For each sample, compounding was performed at $60^{\circ} \mathrm{C}$, at rotor speed of $50 \mathrm{rpm}$ and at a fill factor of $80 \%$ in weight proportions listed in Table 1. After $24 \mathrm{~h}$ conditioning at an ambient temperature of $20^{\circ} \mathrm{C}$ and a relative humidity of $40 \%$, the blends were molded into $125 \times 125 \times 2 \mathrm{~mm}^{3}$ sheets and cured in an electrically heated hydraulic press LabEcon 300 (Fontijne Presses, Netherlands) at $160^{\circ} \mathrm{C}$ under $200 \mathrm{kN}$ force in accordance with the optimum curing time established using a moving die rheometer.

\subsection{Testing}

Cure characteristics of the compounded samples were studied using a Moving Die Rheometer (MDR 3000 MonTec, Germany) according to ISO 3417 at $160^{\circ} \mathrm{C}$.

Each molded sheet of about $2 \mathrm{~mm}$ in thickness was cut into rectangular strips of $45 \times 15 \mathrm{~mm}^{2}$ (length $\times$ width).

DC conductivity was calculated using Equation (1) from the current passed through the sample measured with a programmable electrometer (Keithley $6517 \mathrm{~A}$, USA), at voltage of $3 \mathrm{~V}$ during $300 \mathrm{~s}$ in geometrical center of the strip in a two-point setup, using brass plate electrodes of $15 \mathrm{~mm}$ diameter (Figure 2) as:

$\sigma=\frac{I}{U} \cdot \frac{t}{S}$

where $I$ is current, $U$ is voltage, $t$ is sample thickness [cm] and $S$ is the area of each of the equivalent electrodes $\left[\mathrm{cm}^{2}\right]$. It should be noted that all fatigued samples were conditioned for $60 \pm 5 \mathrm{~min}$ before

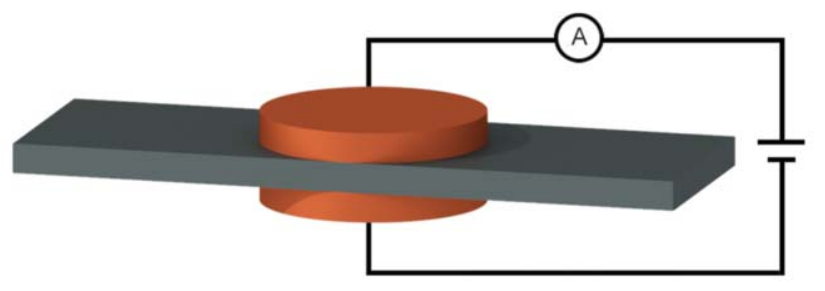

measurements in order to minimize elastic recovering effects.

Fatigue measurements were carried out using Tear and Fatigue Analyzer (Coesfeld GmbH, Germany). The detailed description of the analyzer can be found in $[18,19]$. Sets of 3 samples per compound at each deformation amplitude were analyzed using a frequency of $5 \mathrm{~Hz}$, the test was carried out up to $10^{5} \mathrm{cy}-$ cles. Strain amplitudes were set to be $0.1,0.25$ and 0.50 and initial distance between the clamps was $15 \mathrm{~mm}$ (Figure 3a). The fatigue load was applied using sinusoidal waveform (Figure $3 b$ ), where the pre-stress was set to be $0 \mathrm{MPa}$.

Images of the hybrid fillers and surface of the produced samples were obtained by means of a scanning electron microscope (SEM), model Nova NanoSEM 450 (FEI, USA) with Schottky field emission electron source.

Measurement of crosslink density was done through the equilibrium solvent swelling method in toluene [20]. The samples for test were cut into rectangular

a)

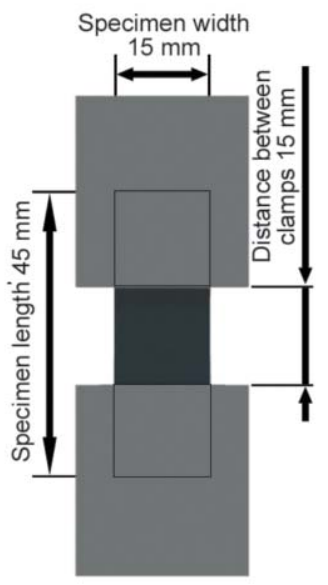

b)

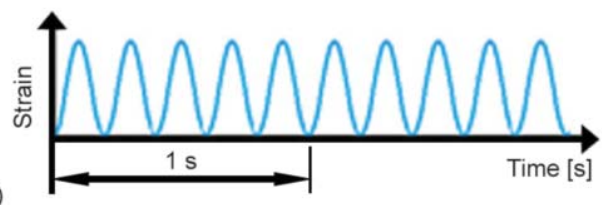

Figure 3. a) Clamping system and specimen dimensions, b) harmonic sinusoidal loading procedure.

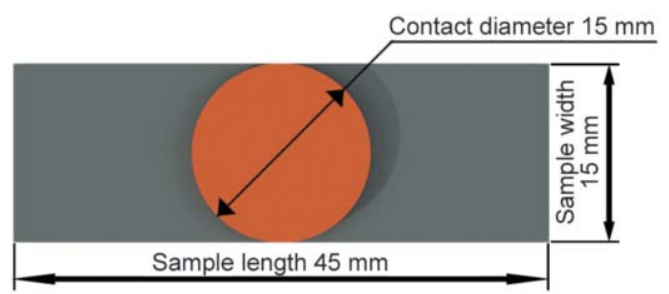

Figure 2. Scheme of testing setup. 
parallelepipeds measuring $15 \times 15 \times 2 \mathrm{~mm}^{3}$ and included the deformed regions of samples after fatigue test and non-deformed regions of as-obtained sheets of rubber composites as well. The test pieces were immersed in toluene at ambient temperature of $21^{\circ} \mathrm{C}$. After $72 \mathrm{~h}$, each sample was withdrawn and the excess of solvent remaining on the surfaces was wiped off with a tissue paper and immediately weighed on an analytical balance. Finally, the sample was dried in a vacuum oven for $12 \mathrm{~h}$ at $50^{\circ} \mathrm{C}$ and weighed again. The cross-link density $v\left[\mathrm{~mol} / \mathrm{cm}^{3}\right]$ was calculated by using the Flory-Rehner equation (Equation (2)) [20]:

$v=\frac{-\left(\ln \left(1-v_{r}\right)+v_{r}+\chi \cdot v_{r}^{2}\right)}{V \cdot\left(v_{r}^{1 / 3}-\frac{v_{r}}{2}\right)}$

where $\chi$ represents the Flory-Huggins interaction parameter between toluene and rubber $(0.39), V$ is the molar volume of toluene $\left(106.3 \mathrm{~cm}^{3} / \mathrm{mol}\right)$. Volume fraction of rubber $\left(v_{\mathrm{r}}\right)$ in the swollen network was calculated by Equation (3):

$v_{\mathrm{r}}=\frac{\frac{W_{\mathrm{d}}-W_{\mathrm{f}}}{\rho_{\mathrm{r}}}}{\frac{W_{\mathrm{d}}-W_{\mathrm{f}}}{\rho_{\mathrm{r}}}+\frac{W_{\mathrm{s}}-W_{\mathrm{d}}}{\rho_{\mathrm{s}}}}$

where $W_{\mathrm{d}}$ is the weight of dried sample, $W_{\mathrm{f}}$ is the weight of the fillers in the sample and $W_{\mathrm{s}}$ is the weight of the swollen sample. $\rho_{\mathrm{r}}$ and $\rho_{\mathrm{s}}$ are the density of rubber $\left(0.911 \mathrm{~g} / \mathrm{cm}^{3}\right)$ and the density of solvent $\left(0.867 \mathrm{~g} / \mathrm{cm}^{3}\right)$ respectively.

\section{Results and discussion}

\subsection{Fatigue dynamic loading}

Figure 4 denotes the stress magnitude required to achieve $0.10,0.25$ and 0.50 defined strain for each group of samples consisting of NR0, NR1, NR3 and NR5. All the investigated samples were subjected to $10^{5}$ fatigue cycles. The data was collected after each 100 cycles starting after first 5 cycles, considered as a pre-strain conditioning.

It can be certainly observed that lower strain amplitude required lower stress for all the samples. CNTs loading increased the stress necessary to reach the fixed strain amplitude. As can be seen, the stabilization of stress-strain relations depended on strain amplitude and the composition of fillers. For 0.10 strain amplitude, stabilization was observed from the beginning (just after preconditioning of 5 cycles) for all the studied compositions. Contrary to this, at 0.50 strain

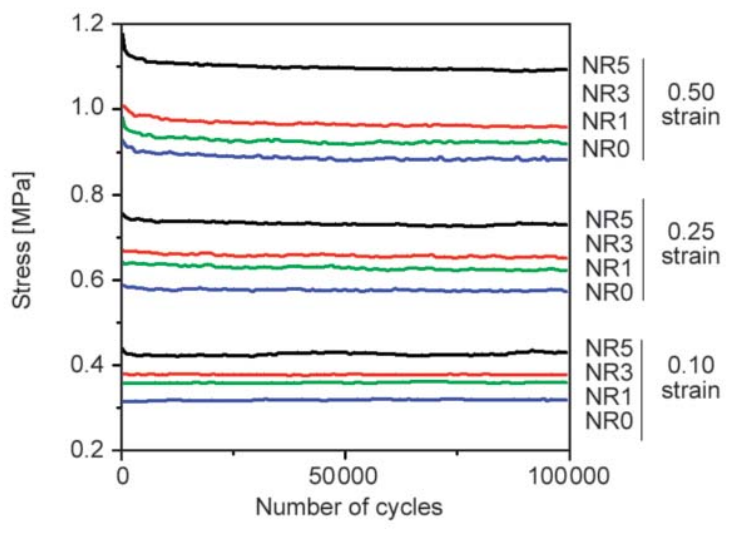

Figure 4. Stress applied to deform samples up to set strain amplitudes $(0.10,0.25$ and 0.50$) v s$. number of fatigue cycles.

testing amplitude, rubber softening lasted up to an unusually high number of 6000 cycles exhibiting the Mullins effect [21]. Whereas, at 0.25 strain amplitude the results were intermediate between the two extremes of 0.10 and 0.50 strains.

\subsection{Electrical conductivity before fatigue test}

Figure 5 shows the DC volume electrical conductivity (calculated using Equation (1)) of the cured samples filled with different ratios of $\mathrm{CNT}+\mathrm{CB}$ hybrid fillers, before the fatigue tests.

Gradual replacement of pre-defined amount of $\mathrm{CB}$ with the same quantity (by weight) of CNTs, namely $0.0,1.0,3.0$, and $5.0 \mathrm{phr}$, led to very essential growth of conductivity, best represented by the logarithmic scale in Figure 5. Current flow through filled polymers is mainly governed by percolation threshold of matrix-filler system and tunneling effect between conductive fillers [22]. Since, the density of CB $\left(\sim 2.2 \mathrm{~g} / \mathrm{cm}^{3}\right)$ is close to those of CNT, volume fraction of hybrid fillers can be considered more or less similar for all tested samples.

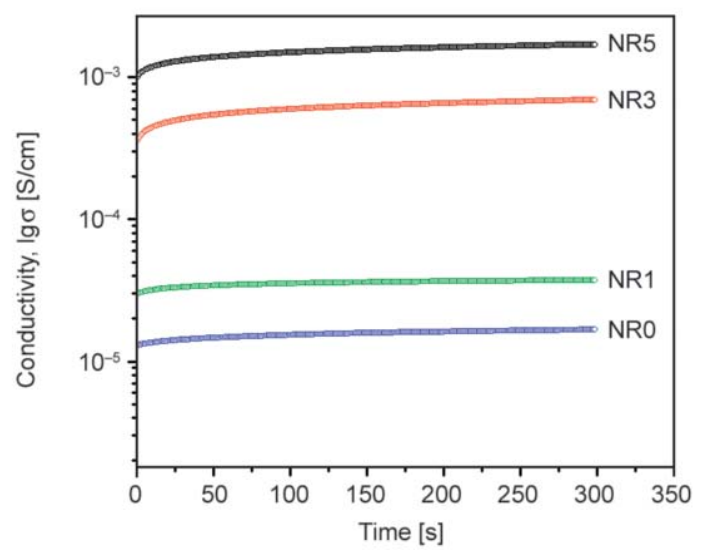

Figure 5. Electrical conductivity of samples before fatigue test. 
A pure CB N220 having the average primary particle diameter of about $21 \mathrm{~nm}$ and surface area $118 \mathrm{~m}^{2} / \mathrm{g}$, exhibits moderate electrical conductivity, $\sigma \sim 2 \mathrm{~S} / \mathrm{cm}$. However, the NR containing $30 \mathrm{phr}$ of CB N220 (samples NR0) showed a conductivity of only $\sim 10^{-5} \mathrm{~S} / \mathrm{cm}$, as is quite expected due to the high volume resistivity of NR.

Addition of CNTs with conductivity $\sim 10^{3} \mathrm{~S} / \mathrm{cm}$, as a part of hybrid fillers, gradually increased the electrical conductivity of $\mathrm{NR} / \mathrm{CB}+\mathrm{CNTs}$ composite up to $\sim 10^{-3} \mathrm{~S} / \mathrm{cm}$ (for samples NR5). The other samples showed somewhat lesser magnitudes, though exhibiting an increasing trend with increase in concentration of CNTs.

Figure 5 also reflects an increase in conductivity as a function of time. The conductivity of the samples increased with time, initially very rapidly, then more slowly, approaching a quasi-equilibrium value. According to [23], the carbon black particles are connected to each other by the flexible long rubber molecules. The flexibility of the rubber molecules allows almost free translational kinetic (Brownian) motion of the carbon black particles, up to the limit given by the length of the rubber molecules and enhances filled polymer conductivity in time.

This phenomenon never stops but after sufficient time, a quasi-equilibrium of conductivity is established.

\subsection{Electrical conductivity after fatigue test}

The conductivity measured after fatigue test was also a time dependent process and presented results (Figure 6) are the arithmetic mean values of each set of samples in the steady-state conductivity regime. For better understanding of the exact magnitudes, the numerical values are presented in Table 2 .

The highest modification in conductivity after fatigue test was observed in case of NR0 where CNTs were absent and the higher fatigue strain amplitude produced higher conductivity degeneration. This trend was generally found for all the compositions

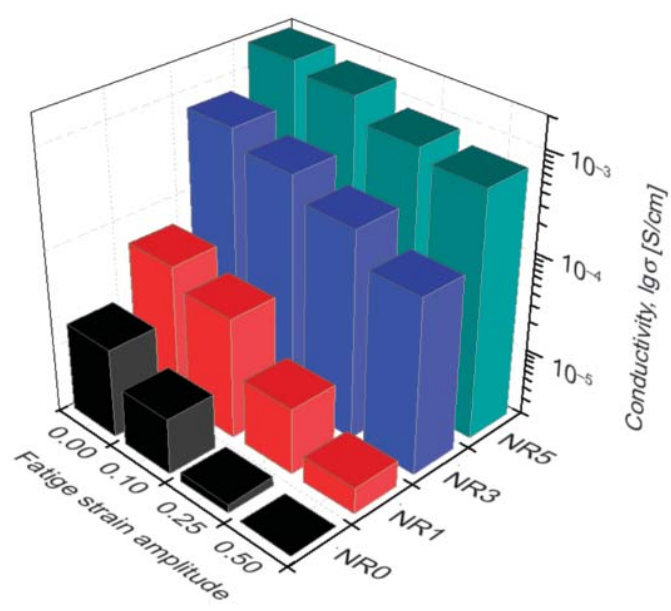

Figure 6. Conductivity of composites before ( 0.0 strain amplitude) and after fatigue test at $0.10,0.25$ and 0.50 strain amplitude $v s$. CNTs concentration in composites: NR0 - $0.0 \mathrm{phr}, \mathrm{NR} 1-1.0 \mathrm{phr}$, NR3 $3.0 \mathrm{phr}$ and NR5 - 5.0 phr of CNTs content.

of the samples. However, increased quantity of CNTs in hybrid fillers preserved the electrical properties of nanocomposites subjected to fatigue processes, in a much better way. For example, after fatigue test at 0.50 strain amplitude samples containing $5 \mathrm{phr}$ of CNTs showed 2.7 times decreased conductivity against 33.3 times decreased conductivity for samples without CNTs.

Generally, for cyclic deformation of vulcanizates at high strains, the material microstructure evolution can be divided into two stages. First is the network decomposition process into a pure rubber network phase and a polymer-filler network phase [24]. The second stage induces more dramatic changes and is characterized by cavitation induced by decohesion between hard particles and soft rubber matrix (for example between zinc oxide and NR [25]).

In the present work, cyclic stretching tests of samples were carried out at low strain amplitudes which were below the mechanical fatigue limit [15] of rubber matrix. Thus, it was assumed that only the filler network was mainly modified leaving the rubber matrix almost intact. SEM analyses of surface morphology

Table 2. Electrical conductivity of samples before and after $10^{5}$ cycles of deformation at $0.10,0.25$ and 0.50 of strain amplitude.

\begin{tabular}{|l|c|c|c|c|}
\hline & $\begin{array}{c}\text { NR0 conductivity } \\
{[\mathbf{S} / \mathbf{c m}]}\end{array}$ & $\begin{array}{c}\text { NR1 conductivity } \\
{[\mathbf{S} / \mathbf{c m}]}\end{array}$ & $\begin{array}{c}\text { NR3 conductivity } \\
{[\mathbf{S} / \mathbf{c m}]}\end{array}$ & $\begin{array}{c}\text { NR5 conductivity } \\
{[\mathbf{S} / \mathbf{c m}]}\end{array}$ \\
\hline Before fatigue test & $1.7 \cdot 10^{-5}$ & $5.8 \cdot 10^{-5}$ & $7.3 \cdot 10^{-4}$ & $1.9 \cdot 10^{-3}$ \\
\hline 0.10 strain, $10^{5}$ cycles & $7.6 \cdot 10^{-6}$ & $3.6 \cdot 10^{-5}$ & $4.8 \cdot 10^{-4}$ & $1.5 \cdot 10^{-3}$ \\
\hline 0.25 strain, $10^{5}$ cycles & $2.5 \cdot 10^{-6}$ & $9.5 \cdot 10^{-6}$ & $2.8 \cdot 10^{-4}$ & $8.8 \cdot 10^{-4}$ \\
\hline 0.50 strain, $10^{5}$ cycles & $5.1 \cdot 10^{-7}$ & $3.7 \cdot 10^{-6}$ & $1.3 \cdot 10^{-4}$ & $6.9 \cdot 10^{-4}$ \\
\hline
\end{tabular}




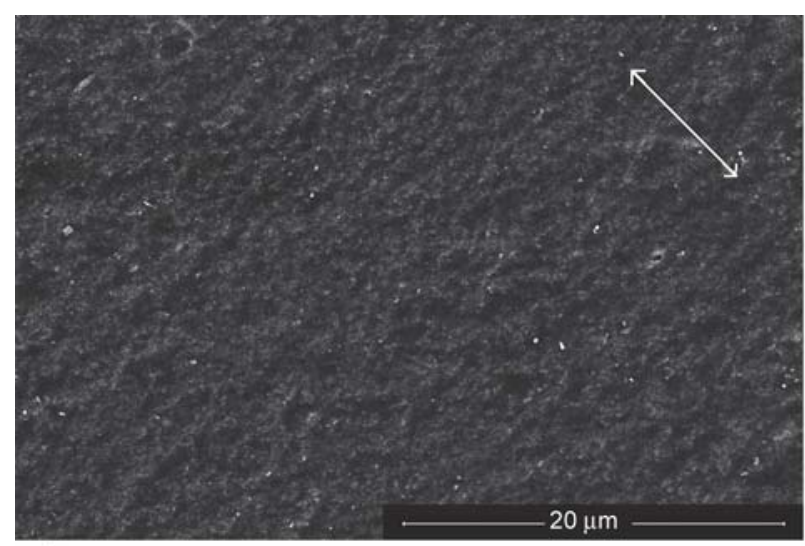

a)

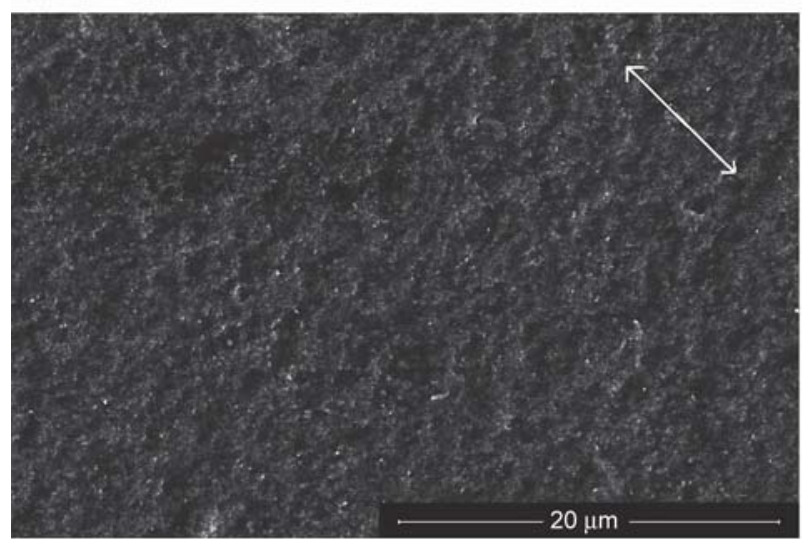

c)

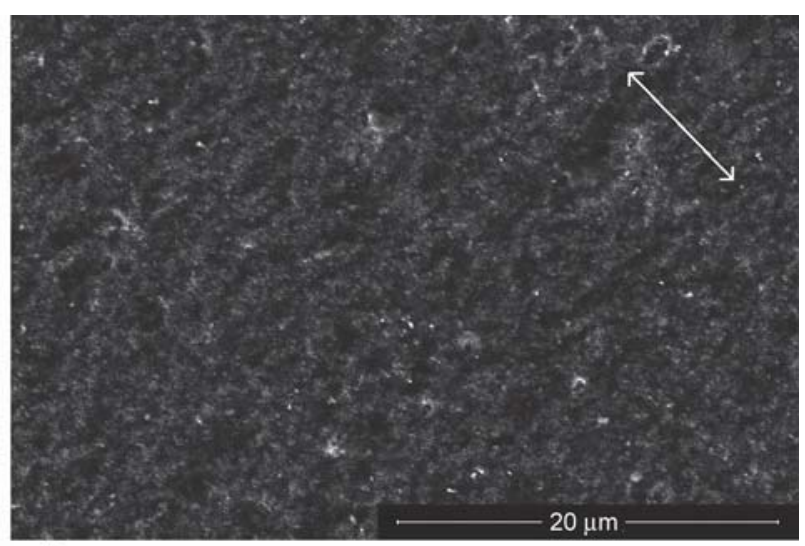

b)

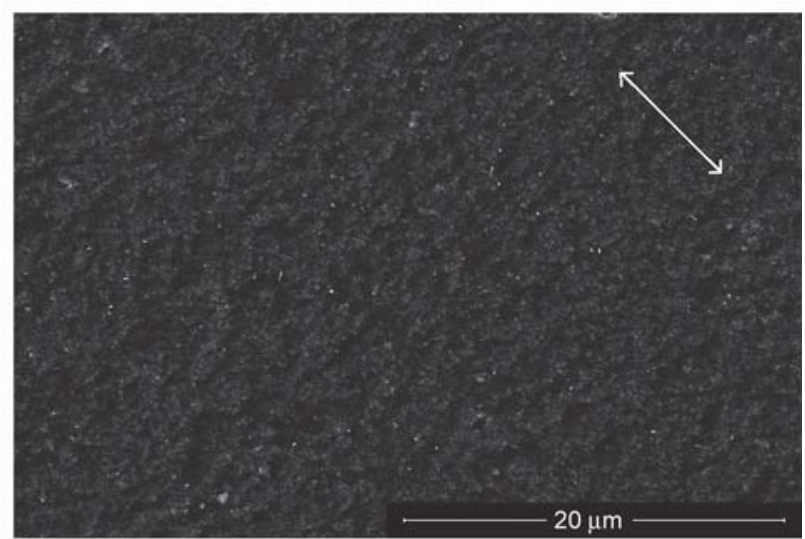

d)

Figure 7. SEM images of in-situ 0.5 strained samples of NR5 composition: a) as obtained, b) after fatigue test at 0.10 test amplitude, c) after fatigue test at 0.25 test amplitude and d) after fatigue test at 0.50 test amplitude. White arrows show the direction of in-situ elongation as well the direction of fatigue test.

of the unfatigued as well as the fatigued samples at all the three test amplitudes revealed lack of cracks in polymer visible at micro level, as is shown in Figure 7. In order to open the cracks and make them observable, the samples were strained at 0.5 during the SEM analyses. The examined morphology of the rubber polymer reflected non-appearance of any cracks at selected magnification as well as no remarkable differences between samples.

Another more sensitive method (besides SEM), to perceive any breaks of rubber matrix even at molecular level is swelling test. Figure 8 summarizes the crosslink density (obtained from Equation (2)) of vulcanizates with different $\mathrm{CB}+\mathrm{CNTs}$ contents before and after fatigue test at different strain amplitudes. The crosslink density of vulcanizates exhibited an increasing trend with an increase in CNTs content. This was attributed to the physical crosslinks between CNTs and natural rubber [20], which immobilized the rubber chains and consequently minimized the amount of the solvent within the rubber matrix at equilibrium swelling. All fatigue tested samples, subjected to different strain amplitudes, showed slight reduction in crosslink density compared to the non-fatigued ones and no significant change with an increase in strain amplitude. This experimentally confirmed that no critical transformation occurred in the rubber matrix during cyclic uniaxial tensile test at the implemented strain amplitudes and number of cycles. On the other hand, electrical conductivity degradation strongly indicated a residual restructuring of conductive paths. Therefore,

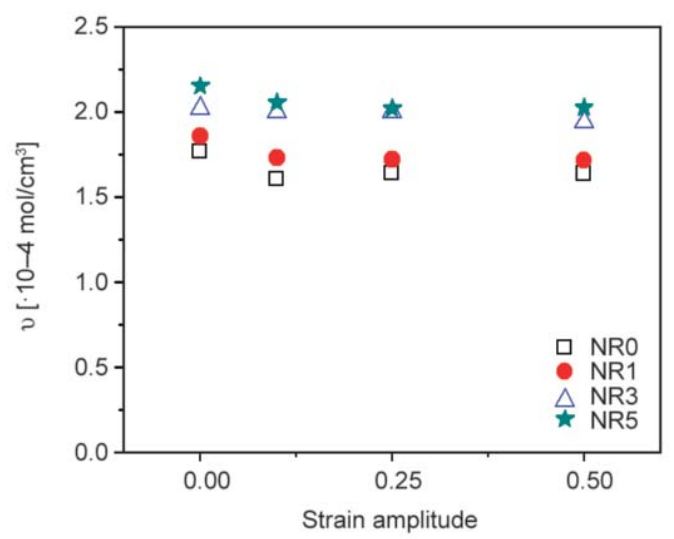

Figure 8. Crosslink density of vulcanizates before and after fatigue test at different strain amplitudes. 
fatigue transformation in investigated vulcanizates at small strain amplitudes (up to 0.5) was predominantly due to reorganization of $\mathrm{CB}$ filler network (filler network breakdown, filler deagglomeration in the framework of self-similarity, polymer debonding from filler surface, strain softening of the polymer shell surrounding fillers, a network junction at small strain, or the jamming transition [26] etc.).

All these processes might have led to significant destruction of the conductive paths which was hypothesized through an indigenous scheme shown in Figure 9. In the figure white lines show the conductive paths which cross the presented region in vertical direction. The blue structures signify nanotubes while red dots are carbon black particles.

The carbon black primary particles almost never exist separately and are strongly fused by covalent bonds into aggregates which join together by van der Waals forces and form agglomerates.

During the external stressed condition, the strain of rubber matrix at the nano level, is assumed to be very non-uniform and filler dependent. The investigated samples could be regarded as a mixture of domains with different elastic modulus and rupture strength (depending on local concentration of fillers). The regions with low concentration of fillers are more stretchable. Due to this strain gradient, it can be assumed that the slipping of molecular rubber chains over surfaces of CB aggregates [27], will be oriented toward the regions with lower concentration of fillers. Thus enlarging of nonconductive regions is accompanied by separation of peripheral aggregates from agglomerates, simultaneous compaction of aggregates which form the core of agglomerates and broad destruction of conductive paths. Due to their high aspect ratio, and surrounding rubber chain immobility [20], CNTs may arrest the increasing or formation

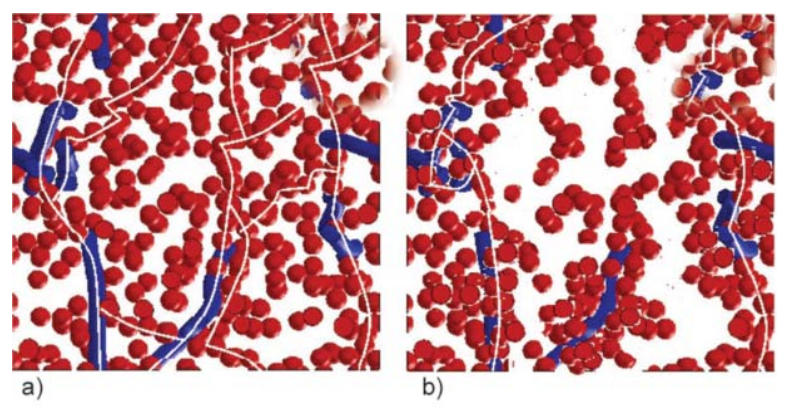

Figure 9. Scheme of conductive paths inside of sample containing hybrid filler: a) before and b) after fatigue test. of nonconductive regions in its vicinity. Thus, the electro-conductive paths containing only $\mathrm{CB}$ are much more affected in the process of desctruction than the paths containing $\mathrm{CB}+\mathrm{CNTs}$. More than that, a fatigued sample is supposed to concentrate the $\mathrm{CB}$ agglomerates around of relatively fixed CNTs and generate CNTs dependent distribution of reformed conductive spots (Figure 9b). These reformations of conductive paths, ultimately led to decreasing of conductivity compared to initial samples but higher concentration of CNTs much better preserve the conductivity in fatigued samples.

\section{Conclusions}

Long lasting cyclic deformation at strain amplitudes up to 0.5 did not exhibit change in NR polymer matrix filled with hybrid filler but substantially changed the residual electrical conductivity of tested samples. With an increase in cyclic deformation amplitude, the residual electrical conductivity of all the samples decreased.

Partial replacement of CB with CNTs definitely improved volume conductivity of the unstrained samples. Also, increasing amount of CNTs in the hybrid systems tended to better preserve the conductivity after cyclic deformation due to its active role in restricting the formation of nonconductive regions between $\mathrm{CB}$ agglomerates. This tendency may be very much appreciated in fabrication of transducers, sensors and flexible electrodes working under elastically deformed conditions as well as in applications for electrostatic rubber products.

Related to the results of the experiments, a new mechanism of 'conductivity preservation' in flexible conductive materials based on $\mathrm{CB}+\mathrm{CNTs}$ hybrid fillers was proposed, and explained through the reorganization of the positions of $\mathrm{CB}$ aggregates against CNTs.

\section{Acknowledgements}

This article was written with the support of Operational Program Research and Development for Innovations co-funded by the European Regional Development Fund and national budget of the Czech Republic, within the framework of the project CPS - strengthening research capacity [reg. number: CZ.1.05/2.1.00/19.0409] as well supported by the Ministry of Education, Youth and Sports of the Czech Republic - Program NPU I [LO1504] and by the internal grant agency of the project IGA/CPS/2019/001. 


\section{References}

[1] Boonstra B. B. S. T., Dannenberg E. M.: Electrical conductivity of rubber-carbon black vulcanizates. Industrial and Engineering Chemistry, 46, 218-227 (1954). https://doi.org/10.1021/ie50529a064

[2] Natarajan T. S., Eshwaran S. B., Stöckelhuber K. W., Wießner S., Pötschke P., Heinrich G., Das A.: Strong strain sensing performance of natural rubber nanocomposites. ACS Applied Materials and Interfaces, 9, 48604872 (2017).

https://doi.org/10.1021/acsami.6b13074

[3] Ishigure Y., Iijima S., Ito H., Ota T., Unuma H., Takahashi M., Hikichi Y., Suzuki H.: Electrical and elastic properties of conductor-polymer composites. Journal of Materials Science, 34, 2979-2985 (1999).

https://doi.org/10.1023/A:1004664225015

[4] Liu P., Liu C., Huang Y., Wang W., Fang D., Zhang Y., Ge Y.: Transfer function and working principle of a pressure/temperature sensor based on carbon black/silicone rubber composites. Journal of Applied Polymer Science, 133, 42979-42988 (2016).

https://doi.org/10.1002/app.42979

[5] Ciselli P., Lu L., Busfield J. J. C., Peijs T.: Piezoresistive polymer composites based on EPDM and MWNTs for strain sensing applications. e-Polymers, 10, 1-13 (2010). https://doi.org/10.1515/epoly.2010.10.1.125

[6] De Focatiis D. S. A., Hull D., Sanchez-Valencia A.: Roles of prestrain and hysteresis on piezoresistance in conductive elastomers for strain sensor applications. Plastics, Rubber and Composites, 41, 301-309 (2012). https://doi.org/10.1179/1743289812Y.0000000022

[7] Salaeh S., Nakason C.: Influence of modified natural rubber and structure of carbon black on properties of natural rubber compounds. Polymer Composites, 33, 489-500 (2012).

https://doi.org/10.1002/pc.22169

[8] Abdul-Salim Z. A. S., Hassan A., Ismail H.: A review on hybrid fillers in rubber composites. Polymer-Plastics Technology and Engineering, 57, 523-539 (2018). https://doi.org/10.1080/03602559.2017.1329432

[9] Dong B., Liu C., Lu Y., Wu Y.: Synergistic effects of carbon nanotubes and carbon black on the fracture and fatigue resistance of natural rubber composites. Journal of Applied Polymer Science, 132, 42075-42083 (2015). https://doi.org/10.1002/app.42075

[10] Harea E., Stoček R., Storozhuk L., Sementsov Y., Kartel N.: Study of tribological properties of natural rubber containing carbon nanotubes and carbon black as hybrid fillers. Applied Nanoscience, 9, 899-906 (2018). https://doi.org/10.1007/s13204-018-0797-6

[11] Nakaramontri Y., Pichaiyut S., Wisunthorn S., Nakason C.: Hybrid carbon nanotubes and conductive carbon black in natural rubber composites to enhance electrical conductivity by reducing gaps separating carbon nanotube encapsulates. European Polymer Journal, 90, 467-484 (2017).

https://doi.org/10.1016/j.eurpolymj.2017.03.029
[12] Ma P-C., Liu M-Y., Zhang H., Wang S-Q., Wang R., Wang K., Wong Y-K., Tang B-Z., Hong S-H., Paik K-W., Kim J-K.: Enhanced electrical conductivity of nanocomposites containing hybrid fillers of carbon nanotubes and carbon black. ACS Applied Materials and Interfaces, 1, 1090-1096 (2009).

https://doi.org/10.1021/am9000503

[13] Huneau B., Masquelier I., Marco Y., le Saux V., Noizet S., Schiel C., Charrier P.: Fatigue crack initiation in a carbon black-filled natural rubber. Rubber Chemistry and Technology, 89, 126-141 (2016).

https://doi.org/10.5254/rct.15.84809

[14] Sun C., Du Z., Nagarajan S., Zhao H., Wen S., Zhao S., Zhang P., Zhang L.: Impact of uniaxial tensile fatigue on the evolution of microscopic and mesoscopic structure of carbon black filled natural rubber. Royal Society Open Science, 6, 181883/1-181883/10 (2019). https://doi.org//10.1098/rsos.181883

[15] Lake J., Lindley P. B.: Fatigue of rubber at low strains. Journal of Applied Polymer Science, 10, 343-351 (1966). https://doi.org/10.1002/app.1966.070100214

[16] Schwatz G., Cerveny S., Marzocca A.: A numerical simulation of the electrical resistivity of carbon black filled rubber. Polymer, 41, 6589-6595 (2000).

https://doi.org/10.1016/S0032-3861(99)00894-0

[17] Yanchenko V. V., Sementsov Y., Melezhyk A. V.: Process for preparation of carbon nanotubes (in Russian). U.A. Patent 69292, Ukraine (2007).

[18] Eisele U., Kelbch S. A., Engels H-W.: The tear analyzer - A new tool for quantitative measurements of the dynamic crack growth of elastomers. Kautschuk und Gummi Kunststoffe, 45, 1064-1069 (1992).

[19] Stoček R., Heinrich G., Gehde M., Kipscholl R.: Analysis of dynamic crack propagation in elastomers by simultaneous tensile- and pure-shear-mode testing. in 'Fracture mechanics and statistical mechanics of reinforced elastomeric blends' (eds.: Grellmann W., Heinrich G., Kaliske M., Klüppel M., Schneider K., Vilgis T.) Springer, Berlin, Vol 70, 269-301 (2013). https://doi.org/10.1007/978-3-642-37910-9 7

[20] Zhan Y. H., Liu G. Q., Xia H. S., Yan N.: Natural rubber/carbon black/carbon nanotubes composites prepared through ultrasonic assisted latex mixing process. Plastics, Rubber and Composites, 40, 32-39 (2011). https://doi.org/10.1179/174328911X12940139029284

[21] Mullins L.: Softening of rubber by deformation. Rubber Chemistry and Technology, 42, 339-362 (1969). https://doi.org//10.5254/1.3539210

[22] Sherman R. D., Middleman L. M., Jacobs S. M.: Electron transport processes in conductor-filled polymers. Polymer Engineering and Science, 23, 36-46 (1983). https://doi.org/10.1002/pen.760230109

[23] Wack P. E., Anthony R. L., Guth E.: Electrical conductivity of gr-s and natural rubber stocks loaded with Shawinigan and R-40 blacks. Journal of Applied Physics, 18, 456/1-456/14 (1947). https://doi.org/10.1063/1.1697676 
[24] Dargazany R., Itskov M.: A network evolution model for the anisotropic Mullins effect in carbon black filled rubbers. International Journal of Solids and Structures, 46, 2967-2977 (2009).

https://doi.org/10.1016/j.ijsolstr.2009.03.022

[25] le Cam J-B., Huneau B., Verron E., Gornet L.: Mechanism of fatigue crack growth in carbon black filled natural rubber. Macromolecules, 37, 5011-5017 (2004). https://doi.org/10.1021/ma0495386
[26] Hentschke R.: The Payne effect revisited. Express Polymer Letters, 11, 278-292 (2017).

https://doi.org/10.3144/expresspolymlett.2017.28

[27] Mostafa A., Abouel-Kasem A., Bayoumi M., El-Sebaie M.: Rubber-filler interactions and its effect in rheological and mechanical properties of filled compounds. Journal of Testing and Evaluation, 38, 347-359 (2010). https://doi.org/10.1520/JTE101942 